\title{
RELAÇÕES ENTRE TEORIA E PRÁTICA: POSSÍVEIS EFEITOS PARA A CONSTITUIÇÃO DOS SUJEITOS DOCENTES E DA FORMAÇÃO EM SERVIÇO
}

\section{Ana Carolina de Viveiros Beltran \\ Universidade de São Paulo/Secretaria \\ Municipal de São Paulo}

\begin{abstract}
Resumo
Este trabalho, baseado nos resultados de uma pesquisa empírica e nos estudos foucaultianos e pós-estruturalistas, intenta analisar as relações que professoras de uma Escola Municipal de Educação Infantil estabeleciam entre teoria e prática e os possíveis efeitos destas para os modos de pensar e agir na profissão e arquitetar os horários coletivos de formação no âmbito do trabalho. A compreensão da prática como consequência de uma teoria aplicada em menor ou maior medida e da teoriacomo fornecedora das respostas às dificuldades encontradas na realidade concreta constituía, não somente a lógica da própria formação em serviço, mas possuía um peso significativo para o grupo de professores pesquisado. Além de provocar a cisão entre os sujeitos da ação prática e da ação teórica, essa crençatendia a distanciar os docentes da formação em serviço e os endereçavam aos saberes da experiência, creditados como tipicamente docentes.
\end{abstract}

Palavras-chave: Teoria; Prática; Formação de professores. 


\title{
RELATIONS BETWEEN THEORY AND PRACTICE: POSSIBLE EFFECTS ON THE CONSTITUTION OF THE SUBJECTS TEACHERS AND IN-SERVICE EDUCATION
}

\begin{abstract}
This work, based onthe results of an empirical research and the Foucauldian and poststructuralists studies, attempts to analyse the relations that teachers of a public school child education established between theory and practice and their possible effects to the ways of thinking and acting in the profession and to devise the collective moments of education in the work. The comprehension of practice as a resultof an apliedtheory greater or lesser extentand the theory as a provider of answers to the difficulties found in reality constituted not only the logic of in-service teacher's education, but also hadsignificant weight to the group of teachers surveyed.In addition tocause a splitbetween the subjects ofthe theoreticalaction and the subjects of the practical action, this belief tended to departthe teachers from in-service education and adressed them to the knowlodgeof experience credited as tipicallyteaching.
\end{abstract}

Key-words: Theory; Practice; Teacher's education. 
Relações entre teoria e prática: possíveis efeitos para a constituição dos sujeitos docentes e da formação em serviço

\section{Introdução}

O presente trabalho deriva-se de uma pesquisa realizada em nível de mestrado entre os anos 2009 e 2012 (BELTRAN, 2012), que objetivou compreender a dinâmica da formação em serviço do município de São Paulo arquitetada através de Projetos Especiais de Ação (PEA) ${ }^{1}$. Para isso, desenvolveram-se uma análise das publicações oficiais e da legislação relativas à formação docenteno município de São Paulo entre os anos de 1989 e 2008 e uma pesquisa empírica constituída da análise de observações, relatos escritos e entrevistas coletados, ao longo de um ano, em encontros semanais com um grupo de professoras em seus contextos de formação em serviço em uma Escola Municipal de Educação Infantil.

As análises foram desenvolvidas sob a perspectiva dos estudos foucaultianos e pós-estruturalistas, tendo como principais diretrizes os três eixos, designados por Foucault, de focos de experiência: as formas de um saber possível; as matrizes normativas de comportamento para os indivíduos; os modos de existências virtuais para prováveis sujeitos. O primeiro foco diz respeito às práticas discursivas como matrizes de conhecimentos possíveis, como formas reguladas de veridicção, que fazem alguns saberes circularem como verdadeiros e outros como falsos. O segundo foco relaciona-se às técnicas e aos procedimentos empreendidos no direcionamento das condutas dos outros, às normas e ao exercício do poder. Por fim, o último foco, refere-se às formas que o indivíduo é levado a compreender-se como objeto a ser pensado, relacionar-se consigo mesmo e a constituir-se como sujeito de um tipo particular (FOUCAULT, 2010a).

As portarias, os documentos e as publicações oficiais, nas mais de duas décadas do PEA como ferramenta formativa, apoiaram diferentes parâmetros de qualidade, modelos de alunos e concepções de ensino. Os PEAs inserem-se, assim, num regime de verdade, acolhendo discursos e

\footnotetext{
${ }^{1}$ Instrumento de trabalho, obrigatoriamente, elaborado pelas escolas, que deve expressar as necessidades formativas institucionais e conduzir as ações dos horários coletivos de formação no âmbito trabalho.

Olh@res, Guarulhos, v. 2, n. 1, p. 373-395. Maio, 2014.
} 
fazendo-os funcionar como verdadeiros, promovendo mecanismos que permitem distinguir os enunciados verdadeiros dos falsos e valorizando certas técnicas e procedimentos para a obtenção da verdade (FOUCAULT, 2010b). Podem-se observar, nas próprias disposições legais e documentos oficiais norteadores dos Projetos Especiais de Ação, procedimentos como os de "retomada" das ações executadas, de "constante reflexão e problematização" ou, ainda, de ação-reflexão-ação e tematização das práticas. São estes movimentos que incitam os sujeitos a darem visibilidade àquilo que fazem através de relatos orais e escritos, por exemplo. Os professores são motivados a atribuírem, através desses procedimentos, sentidos particulares às suas práticas, elaborando formas de agir e pensar a partir de um enquadramento teórico e de uma gramática pedagógica considerados desejáveis.

Os professores são chamados à motivação constante em aprender e a reconhecerem-se, inexoravelmente, incompletos para lidarem com os desafios e as exigências profissionais. Há, nas políticas públicas de formação em serviço, sempre uma defasagem profissional pressuposta, que deve ser mobilizadora da reflexão de si. As novas racionalidades apontam para um docente flexível e disposto a descobrir "novas formas de sentir, pensar e agir no ambiente onde a profissão é exercida e de atribuir significados a seus componentes" (SÃO PAULO, [s.d.]) frente aos desafios educacionais da atualidade, exercitando sua capacidade reflexiva.

Nesse sentido, os professores são incitados a darem visibilidade ao trabalho que realizam em sala de aula. O objetivo é que o professor, ao revelar seus fazeres, coloque os seus saberes em evidência para serem avaliados e desestabilizados em confronto com as didáticas ditas excelentes. Informamlhe, assim, que sua prática é valorizada ao mesmo tempo em que a colocam em xeque através da delimitação dos referenciais conceptivos e metodológicos nos quais a reflexão é autorizada. Os professores acabam por ser motivados a estabelecerem vínculos entre o que fazem e sabem e o que 
Relações entre teoria e prática: possíveis efeitos para a constituição dos sujeitos docentes e da formação em serviço

seria desejável fazer e saber de modo a flexibilizarem-se em subjetividades sobrepostas continuamente.

Alcançando a formação em serviço em suas cenas concretas, em um grupo de professoras de uma Escola Municipal de Educação Infantil da cidade de São Paulo, encontraram-se as pessoas que vivem a profissão no que lhe há de mais cotidiano. Eram elas que realizavam os horários coletivos, dandolhes desenhos próprios e ocupando-os com condutas, sentimentos, crenças e valores, tão heterogêneos quanto singulares.

De acordo com as observações, os relatos escritos e as entrevistas realizadas com as professoras, os termos teoria e prática se mostraram recorrentes nas justificativas que estas elaboravam para suas condutas nos momentos de formação em serviço e nas definições e sentidos atribuídos aos Projetos Especiais de Ação. Não obstante, esses foram termos trazidos para o centro das propostas formativas do Município como uma maneira de autorizar e justificar as mudanças de concepções de ensino e as abordagens pedagógicas valorizadas pelas políticas educacionais.

\section{Teoria e prática: a atividade intelectual e a atividade docente}

No primeiro encontro com o grupo de professoras, observou-se um contexto formativo semelhante a um modelo de aula, no qual a coordenadora explicava o conceito de releitura de obra de artes às professoras, pautada em uma literatura pedagógica da educação da infância. Depois, solicitou-se que, considerando a teorização explicitada, os docentes participassem de uma atividade de releitura atuando como seus pequenos alunos. Por fim, as professoras foram convidadas a descreverem os objetivos de tal proposta.

Poder-se-ia pensar, à primeira vista, julgando as divergências das condutas dos participantes nesse encontro com as cenas presenciadas na maioria dos encontros formativos seguintes, que a dinâmica observada se trataria de uma dramatização do grupo buscando atender o que suporiam ser a expectativa da pesquisadora em relação a uma arquitetura adequada do horário coletivo.

Olh@res, Guarulhos, v. 2, n. 1, p. 373-395. Maio, 2014. 
Os encontros futuros, em contraponto, seriam um retrato mais fidedigno da atuação das professoras nos encontros de formação em serviço.

Contudo, o que se pode observar, nesse primeiro momento, configurou-se como uma "teatralização" do coordenador e das professoras acerca do que consideravam ideal para os encontros de PEA ou, ao menos, um modelo de condução e participação no Projeto razoável para ser apresentado a uma pessoa de fora do grupo, advinda da Universidade.

Pode-se observar um modelo bastante convencional de aula, no qual um conteúdo pedagógico foi exposto às professoras. Um conteúdo referenciado em um livro sobre educação infantil que evidenciava práticas de uma escola considerada exemplar.

Outro referencial, que sustentou o tema do encontro, apesar de não ser explicitado, encontrava-se na portaria, de PEA, $\mathrm{n}^{\circ} 1566^{2}$, que resolvia, para a Educação Infantil, "assegurar a todas as crianças a vivência de experiências significativas e variadas utilizando diferentes linguagens, entendendo as práticas sociais da linguagem oral e escrita como organizadoras dessas experiências" e, ainda, implementar o Programa Rede em Rede: a Formação Continuada na Educação Infantil, que tem como um de seus principais objetivos "buscar a renovação e o aprofundamento do discurso e da prática pedagógica por meio da valorização das linguagens infantis como instrumentos culturalmente elaborados" (SÃO PAULO, [s.d.]).

Portanto, o que se apresentou no encontro coletivo, foi um conteúdo pedagógico valorizado, autorizado e divulgado por um enunciado científico através do livro e por um enunciado oficial das políticas educacionais do Município.

Primeiramente, observou-se uma distinção entre os termos teoria e prática marcada pelos lugares de produção e pelos sujeitos de produção de cada uma delas, isto é, a teoria é produzida por pesquisadores na Universidade,

\footnotetext{
${ }^{2}$ Portaria vigente no período da pesquisa, que dispunha sobre os Projetos Especiais de Ação. Atualmente, está em vigor a portaria ${ }^{\circ} 901 / 2014$.

Olh@res, Guarulhos, v. 2, n. 1, p. 373-395. Maio, 2014.
} 
Relações entre teoria e prática: possíveis efeitos para a constituição dos sujeitos docentes e da formação em serviço

na Academia, em Institutos de pesquisa e por funcionários de alto escalão ou convênios com a Universidade pela Secretaria Municipal de Educação.

A prática, no entanto, é produzida pelos professores na escola, sendo o Projeto Especial de Ação, o espaço para que o coordenador pedagógico intermedeie o acesso docente à teoria a fim de ser adaptada a um modelo didático. Tinha-se, então, um terceiro traço de diferenciação: a linguagem. As professoras, após serem apresentadas aos enunciados teóricos pela mediação do coordenador, traduziam-nos para o plano prático através da simulação de aula e da sistematização de objetivos didáticos. Uma distinção entre teoria e prática determinada, portanto, pelo local e pelos sujeitos de produção e, também, pelo tipo de linguagem que os sujeitos acessa vam os conteúdos pedagógicos.

Em segundo lugar, observou-se uma conexão entre teoria e prática da ordem da aplicabilidade. Os enunciados teóricos, científicos e legais tanto justificavam e autorizavam determinadas práticas em detrimento de outras assim como deveriam viabilizar elementos para que os primeiros fossem traduzidos de um âmbito para outro.

O livro apresentado às professoras pautava-se na experiência de um grupo de pesquisadores estadunidenses em uma escola de Educação Infantil italiana, indicando, assim, que os pressupostos teóricos possuíam uma viabilidade prática no âmbito escolar. Outro indício de aproximação entre teoria e prática foi encontrado na publicação "Orientações Curriculares: Expectativas de aprendizagem e Orientações Didáticas- Educação Infantil”, referência para a construção do PEA, na qual se expõem, como objetivos do documento, "servir de referência para o trabalho dos professores e suscitarlhes uma atitude reflexiva enquanto planejadores dos ambientes de aprendizagens das crianças" e "subsidiar cada professor na estruturação de um programa de atividades para as crianças de sua turma”. (SÃO PAULO, 2007, p. 7). Destacava-se, assim, uma relação estabelecida entre teoria e prática da ordem da aplicabilidade. A teoria como modelo para a realização das práticas de sala de aula.

Olh@res, Guarulhos, v. 2, n. 1, p. 373-395. Maio, 2014. 
A prática, sob tal perspectiva, aparecia como extensão de uma teoria aplicável em maior ou menor medida. Nesse sentido, eram as proposições teóricas ditames para a efetivação das ações na realidade concreta. Segundo Deleuze (apud FOUCAULT, 2010b), costumou-se compreender a relação teoria e prática como um processo de totalização, no qual uma ação seria a consequência da outra.

Essa visão está bastante associada às práticas de reforma, das quais a Educação, não raras vezes, foi alvo. Há uma crença de que "questões políticas, sociais, e educacionais exigem soluções científicas. Acredita-se que a libertação da dominação da natureza e da opressão social, exige conhecimento especializado". (POPKEWITZ, 1984, p. 3, tradução minha).

Desse modo, algumas pessoas são certificadas a representarem as necessidades, os desejos, as esperanças de outras em nome de um mundo melhor, de uma educação mais justa ou de qualquer outro objetivo que emirja como relevante. "A reforma é elaborada por pessoas que se pretendem representativas e que têm como ocupação falar pelo outros, em nome dos outros, e é uma reorganização do poder". (DELEUZE apud FOUCAULT, 2010b, p. 72).

Os intelectuais seriam, nesse contexto, agentes da consciência das pessoas, "funcionários da humanidade" (POPKEWITZ, 1997), promotores de conhecimentos creditados como objetivos e neutros capazes de construir possibilidades sociais e novos arranjos institucionais.

A questão, no entanto, não está no papel do intelectual ou na função da teoria em si, mas no lugar específico que estes ocupam em nossa sociedade. Segundo Foucault (2010b), pensar a posição da teoria e do intelectual em termos de ciência/ideologia tem uma importância secundária com relação ao que é primordial: os efeitos específicos dos discursos verdadeiros. Nas sociedades contemporâneas, 
Relações entre teoria e prática: possíveis efeitos para a constituição dos sujeitos docentes e da formação em serviço

\begin{abstract}
"a verdade" está centrada na forma do discurso científico e nas instituições que o produzem [...] o que se deve levar em consideração no intelectual não é, portanto, “o portador de valores universais"; ele é alguém que ocupa uma posição específica, mas cuja especificidade está ligada às funções gerais do dispositivo da verdade.(FOUCAULT, 2010b, p. 13).
\end{abstract}

Não há uma qualidade repressora e impositiva inerente aos empreendimentos teóricos ou à atividade intelectual ou uma ação originalmente totalizadora. A teoria não totaliza. É o poder que opera por totalizações. (DELEUZE apud FOUCAULT, 2010b).

A transição entre o intelectual universal e o intelectual específico, explorada por Foucault (2010b), oferece um panorama concreto da ligação da verdade com os efeitos de poder, no qual esses profissionais estão implicados. Segundo ele, o intelectual universal era o escritor "livre" que, em oposição aos servidores do Estado ou do Capital, ao despotismo e ao abuso, escrevia em nome da justiça, da equidade, enfim, daquilo que podia e devia valer universalmente. Com o desenvolvimento das estruturas técnico-científicas, o "escritor genial" dá lugar ao "cientista absoluto", o possuidor de conhecimentos locais, setoriais e específicos. O intelectual específico, a serviço do Estado ou contra ele, possui uma relação direta e localizada com a instituição e o saber científicos. Além disso, sua própria posição enquanto portador não de um saber que valha universalmente, mas de um saber endereçado e interessante a toda a humanidade, dá-lhe acesso à "politização", à participação em tomadas de decisões na vida pública, a associações partidárias, de governo, sindicais etc.. Estão, portanto, posicionados em um conjunto de procedimentos regulados para a produção, a lei, a categorização, a circulação, a divulgação e o funcionamento de enunciados.

O intelectual tem uma tripla especificidade: a especificidade de sua posição de classe (pequeno burguês a serviço do capitalismo, intelectual "orgânico" do proletariado); a especificidade de suas condições de vida e de trabalho, ligadas à sua condição de intelectual (seu domínio de pesquisa, seu lugar no laboratório, as exigências políticas a que se submete, ou contra as quais se revolta, na universidade, no hospital, etc.); finalmente, a especificidade da política da verdade nas sociedades contemporâneas. É então que sua posição pode

Olh@res, Guarulhos, v. 2, n. 1, p. 373-395. Maio, 2014. 
adquirir uma significação geral, que seu combate local ou específico acarreta efeitos, tem implicações que não são somente profissionais ou setoriais.(FOUCAULT, 2010b, p. 13).

O posicionamento do intelectual, hoje em dia, apresenta-se, provavelmente, mais difuso e menos evidente quanto poderia ser ao colocar-se contra ou a favor do proletariado. As teorias que, em outros tempos, representavam possibilidades alternativas ao que estava estabelecido podem engendrar, atualmente, os regimes de verdade. Por exemplo, no campo da Educação Municipal, as teorias sócio-construtivistas que apoiavam políticas públicas em prol de processos de redemocratização do país apresentam-se, agora, como pano de fundo de programas vinculados a avaliações externas e em larga escala e propostas de formação de professores bastante prescritivas. Há, portanto, um regime através do qual o discurso científico é tomado como "verdade", que separa a teoria da prática e em que os sujeitos são incitados a pensar-se fora da ação teórica e dela esperar a cura para as mazelas do dia a dia. Colocam-se em questão as conexões que os sujeitos são excitados a estabelecer entre a teoria e a prática, o que no mais tem se configurado como uma tecnologia da própria formação em serviço através do PEA.

Contudo, não era somente a possibilidade de aplicação que avizinhava os enunciados teóricos das práticas concretas das professoras com suas crianças. Por que o tema escolhido pelo coordenador não foi "prontidão para a alfabetização", "invenção da infância"; "governo da infância", "estudos críticos sobre o construtivismo"? Por que, ao dramatizar uma situação ideal de horário coletivo, este conteúdo foi selecionado? Uma das justificativas para a implantação do Programa Rede em Rede, que embasa a formação dos coordenadores pedagógicos e os Projetos Especiais de Ação das Unidades Educacionais, destaca "[...] como importante meta do trabalho pedagógico a questão da apropriação, pelas crianças de 0 a 6 anos, de diferentes linguagens, instrumentos básicos para construírem significações e a própria identidade." (SÃO PAULO, 2006). 
Relações entre teoria e prática: possíveis efeitos para a constituição dos sujeitos docentes e da formação em serviço

Pode-se observar que o trabalho pedagógico envolvendo linguagens variadas é a meta da Secretaria Municipal de Educação para a Educação Infantil. Acrescentam-se, ainda, as considerações sobre "Experiências com a Expressividade das Linguagens Artísticas" do documento "Orientações Curriculares: expectativas de aprendizagens e orientações didáticas Educação Infantil”: "Esse campo reúne aprendizagens desejáveis para que toda criança se aproprie de diversas linguagens que constroem as manifestações artísticas e trabalham a expressividade humana". (SÃO PAULO, 2007, p. 116).

As múltiplas linguagens são reconhecidas pelos documentos municipais como um campo de conhecimento valorizado e desejável para a educação das crianças pequenas. Assim, não somente justificam e autorizam as práticas fundamentadas em tais aportes teóricos como, também, excluem outros enunciados possíveis.

As publicações da Secretaria Municipal de Educação são baseadas substancialmente em referências teóricas das áreas da Psicologia, Didática e Arte que considerem a criança como sujeito histórico e cultural. As "Orientações Curriculares: expectativas de aprendizagens e orientações didáticas", por exemplo, trazem em sua bibliografia o livro apresentado pelo coordenador ao grupo de professoras. O que se quer dizer é que os enunciados teóricos oficiais alcançam as escolas municipais legitimando certas práticas pedagógicas assim como os enunciados teóricos de caráter científico definem aprendizagens e contextos desejáveis para a Educação Infantil.

Não se pretendeu defender ou condenar tais formas de pensar o trabalho pedagógico com as crianças pequenas. A questão é o lugar específico que a teoria ocupava no grupo estudado, no PEA e na sociedade. Procura-se indicar os pontos de contato ou de relação entre os termos teoria e prática no grupo estudado. Um ponto, o da aplicabilidade teórica, isto é, a teoria prescreveria ações e prepararia os sujeitos para uma prática concreta. Outro ponto, os enunciados teóricos definiriam o campo de possibilidades das Olh@res, Guarulhos, v. 2, n. 1, p. 373-395. Maio, 2014. 
práticas de modo que elas fossem consideradas adequadas ou não adequadas, boas ou ruins, aceitáveis ou não aceitáveis.

Uma proposta bastante valorizada nos contextos de formação em serviço, por exemplo, é a tematização das práticas, que, inclusive, é indicada com uma das modalidades de consecução dos Projetos Especiais de Ação (SÃO PAULO, 2008). Tal modalidade consiste em promover meios de os professores darem visibilidade a suas práticas em sala de aula através de relatos escritos ou orais ou outros tipos de registros para, progressivamente, contextualizá-las em uma linguagem e em ações legitimadas em certa base teórica. Oferecem-se, assim, enunciados a partir dos quais as práticas podem ser nomeadas e justificadas e o campo de manobra pelo qual elas são autorizadas a transitar, traduzindo, numa nova linguagem, os elementos da vida social e profissional.

Sobre essa abordagem metodológica no âmbito da formação em serviço, Popkewitz (1997) afirma que as experiências de ensino dos professores são descontextualizadas e reformuladas num conjunto de regras, de obrigações e de valores das ciências cognitivas. As interpretações individuais são separadas de seus contextos sociais e históricos e recolocadas em modelos de raciocínio. O conhecimento reconceituado faz as relações dos processos de escolarização parecerem naturais. Nessa perspectiva,

[...] os professores são encorajados "a monitorar seu próprio pensamento". Tornando publicamente disponível o pensamento privado, a psicologia do raciocínio torna os professores individuais mais abertos à inspeção e à regulação. (POPKEWITZ, 1997, p. 199).

Os vocabulários advindos das ciências psicológicas possibilitaram que as subjetividades das pessoas fossem traduzidas em novas linguagens para condução das escolas, das prisões, das fábricas, enfim, das instituições sociais como também permitiram que as próprias subjetividades e intersubjetividades tornassem-se objetos de gestão racional (relações familiares, dinâmicas de grupo, desenvolvimento mental, higiene etc.). (ROSE, 1998). “Eles tornaram possível pensar na realização dos objetivos 
Relações entre teoria e prática: possíveis efeitos para a constituição dos sujeitos docentes e da formação em serviço

desejados - satisfação, produtividade, sanidade, habilidade intelectual [...]”. (ROSE, 1998, p. 70, tradução minha).

Assim, os Projetos Especiais de Ação, como se pode observar na exemplificação da modalidade de "tematização das práticas", objetivam levar os sujeitos escolares a refletirem sobre si mesmos através de uma linguagem e um terreno teórico reconhecidos como adequados. De certa forma, essa é uma prática de ajuste, na qual conhecimentos acerca dos sujeitos, dos modos que aprendem, da gestão de coletividades, não estão menos implicados e, portanto, não o estão os saberes oriundos do campo psicológico. Além de, tais saberes, encontrarem-se bastante arraigados nas questões relativas à própria criança, a aprendizagem e ao ensino. Como diz Foucault (2006), a psicologia confiscou a maioria dos domínios que cobriam as ciências humanas.

A dinâmica do horário coletivo e as intenções do PEA da Unidade pesquisada reiteravam os termos teoria e prática como extensões de um mesmo processo. Um processo de totalização de um determinado regime de verdade para o exercício da profissão: enunciados teóricos que circulam e funcionam como verdadeiros e, ao funcionarem como verdadeiros, incitam os sujeitos a avaliarem a si mesmos a partir deles; o modo de operar o exame de si e de suas práticas profissionais (teoria que ilumina e transforma as condutas docentes e escolares); a inibição de certos modos de agir e de pensar a profissão etc.

\section{Teoria versus prática: o saber científico-acadêmico e o saber docente}

A formação em serviço instrumentalizada pelo PEA deve gerar registros diários sobre o conteúdo dos encontros coletivos. No grupo pesquisado, esses registros representavam tarefas individuais, ocorridas por revezamento, em que a professora responsável deveria ler, interpretar e preparar uma síntese de um artigo, texto ou outro material de teor didáticopedagógico, selecionado pelo coordenador. Não se evidenciava um

Olh@res, Guarulhos, v. 2, n. 1, p. 373-395. Maio, 2014. 
movimento entre os termos teoria e prática da ordem da aplicabilidade, no qual o docente deveria traduzir o conteúdo do artigo em objetivos didáticos e atividades dirigidas aos alunos. A ação caracterizada, pelo grupo, como "teórica" e "dura", era a relação direta das professoras com um texto acadêmico.

Podia-se dizer, aliás, que as tarefas de ler e, a partir disso, elaborar um registro para o Projeto configuravam-se em atividades "incômodas" para o grupo de professoras. Realizadas por revezamento, não se constituíam uma proposta coletivamente assumida. A relação das professoras do grupo com essa atividade, elaborar o registro de PEA, podia ser evidenciada em diversas situações do cotidiano pesquisado, sendo categorizada como "difícil" e "de pouco interesse".

Contudo, os registros eram necessários para manter o PEA do grupo em ordem e apresentável à oficialidade ${ }^{3}$. Mesmo não sendo a leitura de textos acadêmicos uma atividade apreciada pelo grupo, esta se constituía uma tarefa em que era incitado a realizar com frequência.

As professoras eram, a todo tempo, chamadas a lidar com produções de cunho acadêmico ou oficial e a apresentar o resultado disso publicamente através do livro de registros de PEA. Poder-se-ia, em um primeiro momento, avaliar que os textos selecionados não condiziam com as necessidades formativas das professoras, o que provocaria a recusa docente à leitura, ou ao estudo dos textos selecionados, ou ponderar que os professores resistiam ao esforço intelectual ou às contribuições teóricas ao âmbito escolar, porque preferiam a segurança dos saberes conhecidos à incerteza dos novos conhecimentos.

Os textos selecionados para a leitura e registro, porém, diziam respeito a demandas expressas pelo próprio grupo, como por exemplo, a relação entre família e escola. Então, sendo a relação com a família um aspecto

\footnotetext{
${ }^{3}$ Portaria $n^{\circ} 1.566 / 08$, artigo $4^{\circ}$, refere-se aos dados mínimos que os projetos devem conter, dentre os quais “descrição das fases/etapas”. No artigo $6^{\circ}, \S 1^{\circ}$, relacionado às incumbências da equipe gestora, aponta que esta deve "adotar procedimento para o registro das fases e atividades". O artigo $7^{\circ}, \S 1^{\circ}$, item $f$, explicita como critério avaliativo "o registro de atividades, que deverá ser o mais detalhado possível".
}

Olh@res, Guarulhos, v. 2, n. 1, p. 373-395. Maio, 2014. 
Relações entre teoria e prática: possíveis efeitos para a constituição dos sujeitos docentes e da formação em serviço

expressivo no cotidiano da escola, por que os textos sobre essa temática não mobilizaram uma adesão e uma discussão coletiva do grupo?

Por outro lado, muitas das atividades desempenhadas pelas professoras nos horários coletivos relacionavam-se com os objetivos do Projeto da escola, como a confecção de um cartaz com fotos de uma sequência de atividades, em que foi proposto que as crianças ouvissem histórias, plantassem flores, criassem seus próprios vasinhos com materiais recicláveis.

As atividades encaminhadas às crianças eram, também, endossadas pelos enunciados teóricos oficiais e pelas abordagens teóricas valorizadas e, intensamente, divulgadas sobre a Educação Infantil como contação de histórias, produções realizadas pelas próprias crianças, oportunidades de aprendizagem mais participativas e elaboração de registros através de fotos. Ressalta-se que não se pretendeu avaliar o quanto essas práticas eram fiéis a determinadas abordagens teóricas, mas afirma-se que, em alguma medida, respondiam a discursos pedagógicos legitimados e reconhecidos como adequados para a Educação Infantil. No entanto, por que as atividades encaminhadas aos alunos e evidenciadas através das fotos produzidas pela professora não constituíram o registro do PEA?

De um lado, tinha-se a ação teórica viável de ser registrada no livro do Projeto Especial de Ação e acessada, pelas professoras, através da leitura e da síntese de textos acadêmicos, de capítulos de livros sobre Educação Infantil, de enunciados oficiais e de artigos de revistas educacionais. De outro, apresentava-se um saber docente valorizado pelas professoras e reconhecido, por elas, como aquisição decorrente das vivências com alunos e colegas ao longo dos anos de exercício profissional.

As práticas docentes, mesmo que aparentemente valorizadas nas políticas de formação do Município, são convocadas ao contexto formativo para, progressivamente, tornarem-se inteligíveis através de um referencial teórico específico e serem reintegradas aos sujeitos e ao cotidiano escolar.

Olh@res, Guarulhos, v. 2, n. 1, p. 373-395. Maio, 2014. 
São exemplos disso, os movimentos de "ação-reflexão-ação" e tematização das práticas. Dão-lhes a centralidade para figurarem como coadjuvantes.

A promessa da pesquisa sobre o pensamento do professor, base para tais práticas, é de melhoramento social e progresso a partir do conhecimento que é imediato, local e benéfico para os indivíduos. Porém, o que fazem é redefinir o trabalho docente "de uma maneira que nega seu conhecimento prático e o reformula tornando-o um conhecimento racional, instrumental, organizado pelos especialistas" (POPKEWITZ, 1997, p. 245). Acrescentando-se as palavras de Hargreaves,

As tentativas de controlar o ensino e o modo como os professores ensinam, por via da imposição de certezas científicas espúrias, figuram entre os derradeiros bastiões da modernidade. Tais tentativas justificam intervenções burocráticas continuadas por parte dos administradores na área da educação e legitimam a separação e a superioridade da academia enquanto fonte especializada de saber científico que pode dirigir e decretar aquilo que os professores devem fazer [...]. Não admira, pois, que continue a ser objecto de uma resistência tão tenaz. (HARGREAVES, 1998, p. 69).

A desconfiança acerca da eficiência dos conhecimentos científicos, marcou, no grupo, uma cisão entre a formação/teoria e prática docente/saber da experiência. Nesse sentido, o conhecimento acadêmico e "intelectualizado" era da ordem dos Projetos Especiais de Ação, disponíveis à oficialidade, como retratos da formação. A teoria despontava como algo "duro", "difícil" ou, ainda, o acesso a ela configurava-se como uma atividade penosa ou indesejada. $\mathrm{O}$ conhecimento relacionado a saberes formais ocupavam o lugar dos Projetos enquanto registro de um percurso formativo a ser mostrado às instâncias superiores.

Contudo, não era só isso. As atividades desempenhadaspelas professoras eram passíveis de serem registradas, já que afinadas com os objetivos do próprio PEA da escola e com práticas legitimadas no Ensino Infantil. Porém, eliminou-se a possibilidade de apontá-las no livro de registros. A prática não valia como formação. Assim, não era só como forma de apresentação à oficialidade que a teoria era considerada para o grupo, mas como sendo elemento constitutivo e típico de formação. As práticas

Olh@res, Guarulhos, v. 2, n. 1, p. 373-395. Maio, 2014. 
Relações entre teoria e prática: possíveis efeitos para a constituição dos sujeitos docentes e da formação em serviço

docentes seriam saberes mais "ordinários" e não estariam autorizadas a integrarem os escritos oficiais do Projeto. Afinal, invariavelmente, são chamadas ao centro das propostas formativas para serem recompostas em uma rede de significados vinculados a determinadas teorizações.

Por outro lado, as práticas das professoras estariam imunes aos conhecimentos teóricos sobre a Educação, configurando-se como saberes, autenticamente, docentes.

Esse conhecimento prático pode ser considerado como
"conhecimento da receita", pois parece definir o que é
"necessário" para os propósitos pragmáticos presentes e futuros
nas escolas, fazendo uma separação entre teoria e prática [...].
O conhecimento da receita faz referência às tecnologias de
manejo de classe e do conhecimento experiencial do cotidiano
através do qual o professor organiza e controla a instrução. O
valor dado ao conhecimento da receita do ensino é
continuamente reiterado nas distinções entre "teoria" e
"prática".(POPKEWITZ, 2001, p. 88).

Um saber desempenhar a profissão, aparentemente blindado às teorizações educacionais e às práticas discursivas circulantes no campo, despontava como uma ação livre dos professores. Um saber advindo da "experiência", que confirmaria sua originalidade, de produção autônoma, ignorando as teorizações produzidas em âmbitos exteriores à escola, mas, a ela, dirigidas. Reconhecida como uma prática distinta das arquitetadas através e pelas teorizações relativas à Educação, a troca de experiência era creditada como uma via formativa tipicamente docente. Uma via que tinha início na sala de aula e para ela voltava, assumindo como parâmetro de avaliação e de análise, as práticas e as vivências das colegas de trabalho, sem depender, supostamente, do crivo das produções científicas e acadêmicas.

O que se apresentava era um sujeito da prática em oposição ao sujeito da ação teórica, que se instrumentalizava no exercício da profissão e na troca de experiências com seus pares, angariando um acervo de respostas úteis e pontuais às demandas do cotidiano escolar. Deve-se acrescentar que o tempo de experiência trazia um estatuto de autoridade às professoras mais

Olh@res, Guarulhos, v. 2, n. 1, p. 373-395. Maio, 2014. 
antigas, que moldavam, nesse caso, uma maneira particular de participação nos horários coletivos, definida pelo descarte da formação por parte desses docentes. Dessa forma, falas que relacionavam a necessidade de formação ao tempo de serviço no magistério mostravam-se recorrentes de modo que as professoras mais antigas eram "autorizadas" a prescindir da participação nas propostas formativas.

A aquisição do "conhecimento da receita" era atribuída ao tempo e à troca de experiência em oposição a uma formação centrada na leitura e no estudo de teorizações do campo educacional. Eram comuns falas que indicavam a descartabilidade da formação em serviço para as professoras mais antigas, a associação entre tempo de exercício de magistério e competência profissional, a relevância dos conselhos dos docentes mais velhos para a execução ou não de algumas práticas de trabalho dos mais jovens, a assunção da troca de experiências como uma fonte privilegiada de conhecimento pedagógico para a lida profissional.

Segundo Popkewitz (2001), a sabedoria da prática está sedimentada em um conjunto de crenças e de valores e em procedimentos generalizáveis para o ensino que determinam os limites para as ações das crianças, das famílias e da atuação do próprio professor, estipulando "o que funciona" no ensino.

\footnotetext{
Por isso, as receitas e as práticas de ensino colocam alguns limites ao que é aceitável, "normal" e razoável na classe, bem como ao que é inaceitável, anormal e não-razoável no ensino. Conjuntos de normas específicas são privilegiados através da sabedoria da prática" e das preocupações com relação ao manejo psicológico das crianças. [...] Nesse sentido, a prática não é algo orgânico às atividades dos professores. Mas, em um sentido mais profundo, o raciocínio experiencial do professor é um efeito de poder" (POPKEWITZ, 2001, p. 90).
}

Os saberes advindos do tempo de experiência não estão, portanto, "flutuando" no corpo social ou encapados por uma armadura blindada aos discursos sobre o ensino e às relações de poder. Eles tanto colocam em prática normalizações referentes ao ensino e às visões sobre famílias e infância, configurando-se como instrumentos de poder, como, também, são afetados por práticas discursivas que fornecem modos de compreender a 
Relações entre teoria e prática: possíveis efeitos para a constituição dos sujeitos docentes e da formação em serviço

educação, a formação, as crianças, enfim, o mundo de uma maneira particular e, portanto, constituem-se como efeitos do poder.

Isso quer dizer que as práticas docentes não se relacionavam, apenas, aos saberes advindos do tempo de experiência que davam conta das demandas do dia a dia profissional, mas, também, diziam respeito às concepções sobre aquilo que seria definido como próprio da infância, do ensino, da escola etc. Devido à abdicação docente às propostas de formações mais diretivas, tais concepções e práticas de ensino podiam ser compreendidas como naturais e típicas à infância ou autenticamente docentes conquistadas pelo tempo de experiência. Entendidas como próprias da infância ou da docência tendiam a tornarem-se inquestionáveis. O risco está em ignorar as empreitadas mais difusas e sutis do poder que, por exemplo, fazem circular como verdadeiros determinados modos de ensino, visões de infância e procedimentos pedagógicos.

Esse, talvez, fosse um dos efeitos mais nefastos da política do PEA no grupo pesquisado. As professoras não conseguiam imaginar outros caminhos formativos, se não aqueles desenhados por um processo totalizador entre teoria e prática. Como este não se cumpria efetivamente, distanciavam-se da formação e prosseguiam na docência, crendo que os saberes úteis eram provenientes do próprio exercício da profissão e blindados às teorizações. $\mathrm{O}$ fato é que, dessa forma, condicionaram-se a pensar por duas vias: a da teoria como oferta de respostas às dificuldades encontradas na realidade concreta, a qual não se concretizava; e a dos saberes advindos do "tempo de experiência", que, como se viu, baseiavam-se em uma série de normalizações sobre o ensino, mas que, por serem creditados como naturais e tipicamente docentes, não eram questionados.

Comprometia-se, portanto, mais do que a formação, constrangendo-se aquilo que deveria ser sua força vital: o exercício do pensamento. O novo, o inédito e o improvável ficavam descobertos como situações externas à atividade docente, cabíveis aos especialistas, no limbo do improcedente. 
E isso valia, não somente para os acontecimentos do cotidiano escolar como também para as maneiras de se constituir como professor.

\section{Considerações finais}

A formação em serviço, como um conjunto de múltiplos acontecimentos localizados em um espaço e em um tempo definidos, mostrou-se um campo aberto de possibilidades. Dele, a teoria e a prática emergiram como termos importantes para as professoras definirem a profissão e a formação e organizarem seus pensamentos e suas condutas em relação às propostas formativas, oficialmente, estruturadas através do PEA.

A teoria e a prática eram concebidas, pelos participantes do grupo, como ações complementares de um processo de totalização, no qual a primeira deveria iluminar e oferecer soluções a segunda. Os dois termos deveriam estar ligados pela possibilidade de aplicação da teoria na realidade concreta, fornecendo a esta uma condição melhor. Assim, delimitavam-se os sujeitos, os lugares e as linguagens da ação teórica e da ação prática.

A atividade intelectual, não se configurando como uma atividade tipicamente docente, despontava como uma tarefa desagradável ao grupo. Porém, constituía-se como representante da formação oficial, devendo ser apresentada, nos livros de registros de PEA, através de sínteses de textos acadêmicos ou de revistas educacionais.

Refutando as teorizações do campo como férteis à formação, as professoras apegavam-se a seu "saber-fazer" conquistado ao longo dos anos de exercício profissional. Esse "conhecimento da receita", opondo-se aos advindos das teorias e do pensamento educacional, era creditado como tipicamente docente.

Contudo, os saberes docentes carregavam-se de normalizações produzidas por uma gama de discursos que alcança a educação e a sociedade, estabelecendo o que seria próprio da infância e da docência. Desse modo, o 
Relações entre teoria e prática: possíveis efeitos para a constituição dos sujeitos docentes e da formação em serviço

"conhecimento da receita" não estava tão blindado às teorizações como acreditavam as professoras, mas sua naturalização, o mantinha inquestionável.

Além disso, a aspiração de que a teoria apresentasse soluções imediatamente transponíveis às situações práticas não se materializava, o que fazia com que as professoras tendessem a aumentar a desconfiança sobre a relevância das teorizações para os espaços concretos de exercício da profissão e a afastarem-se dos contextos formativos.

Nesse sentido, não caberia pensarmos relações diferentes às, habitualmente, propostas entre teoria e prática? Para Deleuze e Foucault (2010b), as relações entre teoria e prática são muito mais parciais e fragmentárias, sendo que nenhuma teoria pode se desenvolver sem encontrar uma espécie de muro, de obstáculo, que necessita da prática para ser atravessado. Ambas são ações, ação teórica e ação prática, que se distinguem e operam por revezamentos. "A prática é um conjunto de revezamentos de uma teoria a outra e a teoria um revezamento de uma prática a outra." (DELEUZE apud FOUCAULT, 2010b, p. 69 e 70) E, por isso, a teoria não é uma prática a ser aplicada, ela mesma é uma prática, que se multiplica a cada choque com as realidades concretas.

Além disso, e por final, abdicando-se da teoria e do pensamento educacional, as professoras abriam mão das histórias que permitem a reinvenção do cotidiano e da própria profissão.

[...] somos filhos e seguidores de uma longa tradição, bem mais antiga do que nós. Uma tradição de educar as novas gerações; ensinar-lhes; governar suas atitudes, hábitos, sentimentos; discipliná-las, para que vivam e sobrevivam, relativamente bem, no tempo e espaço que lhes tocou viver.

Agora... nós não podemos negar e destruir totalmente essa tradição. Mesmo quando nos opomos a ela; mesmo quando a acusamos por seus efeitos negativos; quando criticamos seus equívocos; quando dizemos que, dela, nada queremos nem esperamos, ainda é dela que estamos nos ocupando. (CORAZZA, 2005, p. 7).

Olh@res, Guarulhos, v. 2, n. 1, p. 373-395. Maio, 2014. 
Se os professores abortarem essa tradição, de quem serão filhos, discípulos, mestres, autores e guias? O que terão às mãos no jogo com as relações de poder? Com que armas lutarão diante do assombro das atuais incertezas e da eminência da ignorância reciclada a cada novo conhecimento necessário? Se, em meio a conhecimentos, ideias e valores que se desatualizam e atualizam velozmente, a abstenção à teoria e ao pensamento educacional for uma opção, não se estaria, portanto, produzindo ignorância generalizada? 
Relações entre teoria e prática: possíveis efeitos para a constituição dos sujeitos docentes e da formação em serviço

\section{Referências}

BELTRAN, A. C. V. B. Projetos Especiais de Ação: um estudo sobre a formação em serviço de professores do município de São Paulo. 2012. Dissertação (Mestrado) Faculdade de Educação, Universidade de São Paulo, 2012.

CORAZZA, S. M. Nos tempos da educação: cenas de uma vida de professora. Revista da ABEM, Porto Alegre, v. 12, p. 7-10, mar. 2005.

FOUCAULT, M. Problematização do sujeito: psicologia, psiquiatria e psicanálise. Rio de Janeiro: Forense Universitária, 2006. (Coleção Ditos e Escritos, 1). O governo de si e dos outros. São Paulo: WMF Martins Fontes, 2010a. Microfísica do poder. Rio de Janeiro: Graal, 2010b.

HARGREAVES, A. Os professores em tempos de mudança: o trabalho e a cultura dos professores na Idade Pós-Moderna. Portugal: McGraw-Hill, 1998.

POPKEWITZ, T. S. Paradigm \& ideology in educatioanl research: the social functions of the intellectual.London/New York: The Falmer Press, 1984.

Reforma educacional: uma política sociológica. Porto Alegre: Artmed, 1997.

Lutando em defesa da alma. Porto Alegre: Artmed, 2001.

ROSE, N. Inventing ourselves: psychology, power and personhood. New York: Cambridge University Press, 1998.

SÃO PAULO (Município). Portal da Secretaria Municipal de Educação. [s.d.]. Disponível em: <http://portalsme.prefeitura.sp.gov.br/default.aspx>. Acesso em: 15 maio 2011.

Portaria $\mathrm{n}^{\circ}$ 938, de 2006. Disponível em:

<http://www3.prefeitura.sp.gov.br/cadlem/secretarias/negocios_juridicos/cadlem/integra.asp? alt=15022006P\%20009382006SME $>$. Acesso em: 15 jan. 2010.

Portaria ${ }^{\circ} 1.566$ de 19 de março de 2008. Disponível em:

<http://www3.prefeitura.sp.gov.br/cadlem/secretarias/negocios_juridicos/cadlem/integra.asp? alt=19032008P\%20015662008SME $>$. Acesso em: 15 jan. 2011.

SÃO PAULO (Município). Secretaria Municipal de Educação. Diretoria de Orientação Técnica. Orientações curriculares: expectativas de aprendizagens e orientações didáticas para Educação Infantil. São Paulo, 2007. 